\title{
The exposure of children (5-12 years) and adults (18-65 years) to pesticide residues in their diets
}

\author{
A. Connolly, A. Hearty, A. Nugent and M. J. Gibney \\ UCD Institute of Food \& Health, School of Agriculture, Food Science and Veterinary Medicine, UCD, Belfield, \\ Dublin 4, Republic of Ireland
}

Iprodione, thiabendazole, cyprodinil and chloropyrifos represent four pesticide residues commonly detected in foods available on the Irish market ${ }^{(1)}$. Exposure assessments to these pesticides were conducted on a sample of the Irish population (children aged 5-12 years and adults aged 18-65 years). A number of resources were utilized to conduct these assessments: the National Food Residue Databases $(2005-7)^{(1)}$, which are comprehensive databases for chemical residues and contaminants in food in Ireland; The North/South Ireland Food Consumption Survey (1997-9) ${ }^{(2)}$ and The National Children's Food Survey (2003-4) ${ }^{(3)}$, which are representative food consumption surveys. A total of 286 food groups were developed using data from the food consumption surveys. CREMe software (Crème Software Ltd, Dublin, Republic of Ireland), was used to investigate the exposure of Irish children and adults to the target pesticides. For these assessments distributions of concentrations were used when available for the food group. Where no concentration data were available, instead of assuming the residue value was 0 , one-tenth of the limit of quantification (LOQ) value was used.

The Table shows exposure to actual pesticide concentrations (supplied by the National Food Residue Databases) for both the children and the adults.

Table. Pesticide exposure at actual concentration (including $0.1 * \mathrm{LOQ}$ ) for children and adults

\begin{tabular}{|c|c|c|c|c|c|c|c|}
\hline \multirow[b]{3}{*}{ Pesticide } & \multirow[b]{3}{*}{ Category } & \multirow{3}{*}{$\begin{array}{l}\text { ADI }(\mathrm{mg} / \mathrm{kg} \\
\text { BW per d) }\end{array}$} & \multicolumn{5}{|c|}{ Actual concentration } \\
\hline & & & \multicolumn{2}{|c|}{$\mathrm{mg}$} & \multirow[b]{2}{*}{$\%$ ADI } & \multicolumn{2}{|c|}{ P99.9 } \\
\hline & & & Mean & SD & & $\mathrm{mg}$ & $\% \mathrm{ADI}$ \\
\hline \multirow[t]{2}{*}{ Iprodione } & Children & 0.06 & 0.00008 & 0.00049 & 0.14 & 0.00616 & 10.3 \\
\hline & Adults & 0.06 & 0.00014 & 0.00048 & 0.23 & 0.00487 & 8.14 \\
\hline \multirow[t]{2}{*}{ Cyprodinil } & Children & 0.03 & 0.00001 & 0.00002 & 0.30 & 0.00020 & 0.68 \\
\hline & Adults & 0.03 & 0.00005 & 0.00004 & 0.16 & 0.00047 & 1.58 \\
\hline \multirow[t]{2}{*}{ Chloropyrifos } & Children & 0.1 & 0.00006 & 0.00020 & 0.63 & 0.00172 & 17.2 \\
\hline & Adults & 0.1 & 0.00010 & 0.00020 & 0.98 & 0.00188 & 18.8 \\
\hline \multirow[t]{2}{*}{ Thiabendazole } & Children & 0.1 & 0.00068 & 0.00221 & 0.68 & 0.02609 & 26.1 \\
\hline & Adults & 0.1 & 0.00045 & 0.00162 & 0.45 & 0.01861 & 18.6 \\
\hline
\end{tabular}

ADI, acceptable daily intake; BW, body weight; P99, 99th percentile.

As a result of these exposure assessments, it is clear that intakes of the target pesticides for both children and adults are well below the ADI values. Further analysis of these results also indicated that the fruit and vegetables food groups were the primary contributors to pesticide intake in the Irish diet, with approximately $92 \%$ of thiabendazole and approximately $83 \%$ of chlorpyrifos detected in fruit food groups. Similarly high percentages were detected for iprodione and cyprodinil in the fruit and vegetable food groups.

1. Ashtown Food Research Centre, TEAGASC (2009) National Food Residue Database 2005-2007. http://nfrd.teagasc.ie/

2. Irish Universities Nutrition Alliance (2001) The North/South Ireland Food Consumption Survey 1999. http://www.iuna.net/survey_contents.htm

3. Irish Universities Nutrition Alliance (2004) The National Children's Food Survey. http://www.iuna.net/childrens_survey/ 